13

\title{
Новый метод определения параметров неоднородности термоэмиссии материалов катодов СВЧ приборов
}

\author{
() В.И. Капустин, ${ }^{1}$ И.П. Ли, ${ }^{2}$ А.В. Шуманов ${ }^{1,2}$ \\ ${ }^{1}$ Московский технологический университет (МИРЭА), \\ 119454 Москва, Россия \\ ${ }^{2} \mathrm{AO} \ll$ Плутон», \\ 105120 Москва, Россия \\ e-mail: kapustin@mirea.ru
}

(Поступило в Редакцию 6 июля 2017 г.)

Разработан новый метод исследования параметров неоднородности термоэмиссии катодных материалов, позволивший путем обработки вольт-амперных характеристик определить температурные зависимости среднего размера центров термоэмиссии на поверхности катодов, среднего расстояния между центрами термоэмиссии, относительной площади эмиссионно-активной поверхности катодов и истинного значения работы выхода эмиссионно-активных центров на поверхности катодов. Метод апробирован при исследовании оксидно-никелевых, агломерированных оксидно-никелевых и импрегнированных катодов.

DOI: 10.21883/JTF.2018.03.45609.2417

\section{Введение}

Материалы катодов электровакуумных СВЧ приборов представляют собой металлооксидные композиции, различающиеся составом металлической и оксидной фаз и технологией изготовления $[1,2]$. Оксидно-никелевые катоды (Nickel-Oxide Cathodes - NOC) получают прессованием и спеканием порошка никеля и порошка тройного карбоната бария-кальция-стронция [3]. Агломерированные оксидно-никелевые катоды (Agglomerated Nickel-Oxide Cathodes - ANOC) получают спеканием порошка никеля и агломератов из более мелкого порошка никеля, покрытого тройным карбонатом бария-кальция-стронция [3]. Импрегнированные катоды (Impregnated Cathodes - IC) получают пропиткой пористой вольфрамовой матрицы расплавом алюмината бария-кальция [4-7].

Bo всех типах катодов эмиссионно-активный компонент катода - кристаллиты оксида бария - выделяется на этапе активирования катода в результате термического разложения тройного карбоната или алюмината при прогреве катода в вакууме, при этом материал металлической матрицы является как катализатором разложения исходного карбоната или алюмината, так и инициатором формирования в образующихся кристаллитах оксида бария кислородных вакансий $[8,9]$, определяющих эмиссионные свойства кристаллитов оксида бария [10]. Так как взаимодействие металлической и карбонатно-алюминатной фаз протекает по их границам, это и определяет природу эмиссионной неоднородности поверхности катодов и структуру эмиссионно-активных центров на поверхности катодов. При этом параметрами, характеризующими эмиссионную неоднородность катодов, являются средний размер эмиссионно-активных кристаллитов оксида бария, среднее расстояние между ними и относительная площадь эмиссионно-активной поверхности катода.

В настоящее время известно несколько методов исследования эмиссионной неоднородности катодных материалов. Наиболее наглядным является применение эмиссионного микроскопа, позволяющего визуально регистрировать изменение плотности центров термоэмиссии от температуры катода $[11,12]$, однако разрешающая способность такого микроскопа недостаточна для определения среднего размера активных центров термоэмиссии. Наиболее популярной методикой оценки эмиссионной неоднородности катодов [13] является метод Мирама (Miram), разработанный компанией „E Beam Inc.“, USA. В основе метода лежит эмпирически установленная корреляция между формой и положением кривой „работа выхода - плотность тока термоэмиссии“" и характером неоднородности термоэмиссии катода. Физическое обоснование данной методики, основанное на теории работы катодов [10], было предложено в работе [14].

Настоящая работа посвящена разработке нового метода измерения параметров неоднородности термоэмиссии катодных материалов, основанного на детальном анализе вольт-амперных характеристик катодов, позволяющем определять температурные зависимости среднего размера центров термоэмиссии на поверхности катодов, среднего расстояния между центрами термоэмиссии, относительной площади эмиссионно-активной поверхности катодов и значения эффективной и истинной работ выхода кристаллитов оксида бария.

\section{1. Теоретическое обоснование метода}

С учетом технологий изготовления катодов структуру поверхности композиционных катодных материалов можно представить в виде, показанном на рис. 1 для 


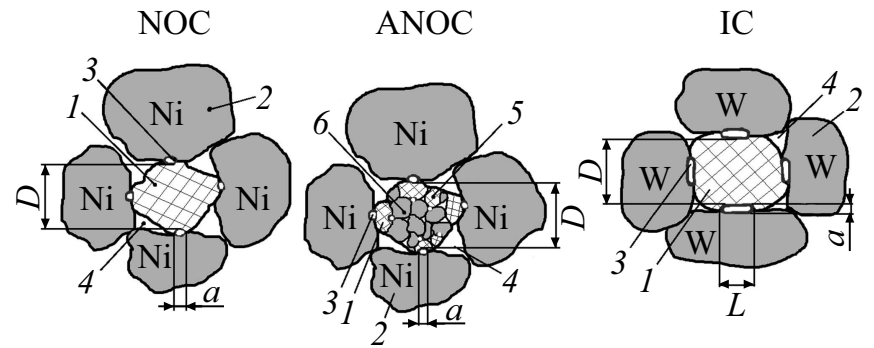

Рис. 1. Структура композиционных катодов СВЧ приборов: оксидно-никелевого (слева), агломерированного оксидноникелевого (по центру), импрегнированного (справа).

NOC, ANOC и IC. На рис. 1 обозначено: 1 - зерна тройного карбоната или алюмината, 2 - зерна никеля или вольфрама, 3 - зерна оксида бария на границе металлической и алюминатной или карбонатной фаз, 4 - поры, 5 - зерна тройного карбоната в составе агломерата, 6 - зерна никеля в составе агломерата, $D$ - среднее расстояние между кристаллитами оксида бария. Форму кристаллитов оксида бария в местах контакта металлической и карбонатной фаз в NOC и ANOC, изготовленных путем прессования соответствующих порошков, можно представить в виде сфер диаметром $a$. Форму кристаллитов оксида бария в местах контакта металлической и алюминатной фаз в IC, изготовленных пропиткой пористой матрицы, - в виде цилиндров диаметром $a$ и длиной $L$.

Для области насыщения термоэлектронная эмиссия с поверхности катода, т.е. с кристаллитов оксида бария, составит [15]

$$
I=S^{*} A_{0} T^{2} \exp \left[-\frac{\varphi^{*}-e\left(\frac{e K_{1}}{4 \pi \varepsilon_{0}}\right)^{1 / 2} E^{1 / 2}}{k T}\right],
$$

где $S^{*}$ - площадь центров термоэмиссии, $k-$ постоянная Больцмана, $T$ - температура, $e-$ заряд электрона, $\varphi^{*}$ - истинная работы выхода кристаллитов оксида бария, $\varepsilon_{0}$ - диэлектрическая постоянная, $E-$ напряженность электрического поля в зазоре катод-анод, $K_{1}-$ константа, характеризующая усиление электрического поля у поверхности сферических или цилиндрических кристаллитов оксида бария, $A_{0}$ - постоянная Ричардсона.

Для модели сферических центров термоэмиссии величина $\mathrm{S}^{*}$ равна

$$
S^{*} \approx S \frac{\gamma n a^{2}}{(D+a)^{2}}
$$

где $S$ - площадь катода, с которой регистрируется термоэмиссия, $n$ - число центров термоэмиссии в квадрате со стороной $D, \gamma$ - относительная площадь поверхности катода, занятая карбонатной фазой.
Для модели цилиндрических центров термоэмиссии $S^{*}$ равна

$$
S^{*} \approx S \frac{\gamma n a L}{(D+a)^{2}},
$$

где $n$ - число центров термоэмиссии в квадрате со стороной $D, \gamma$ - относительная площадь поверхности катода, занятая алюминатной фазой.

Для сферических центров термоэмиссии истинная напряженность поля $E^{*}$ у поверхности кристаллитов оксида бария будет определяться константой $K_{1}=2 d / a$ и напряжением $U$ в зазоре катод-анод [15], где $d-$ расстояние катод-анод

$$
E^{*}=\frac{2 U}{a}=\frac{2 d}{a} \frac{U}{d}=K_{1} E .
$$

Для цилиндрических центров термоэмиссии константа $K_{1}=2 d / a \ln (2 d / a)$, а напряженность поля $E^{*}$ будет равна [15]

$$
E^{*}=\frac{2 U}{a \ln \left(\frac{2 d}{a}\right)}=\frac{2 d}{a \ln \left(\frac{2 d}{a}\right)} \frac{U}{d}=K_{1} E .
$$

Если прологарифмировать соотношение (1), то в области насыщения тока термоэмиссии экспериментальная вольт-амперная характеристика при фиксированной температуре будет иметь вид

$$
\ln I=\ln \left(S^{*} A_{0} T^{2}\right)-\frac{\varphi^{*}}{k T}+\left[\frac{e}{k T}\left(\frac{e K_{1}}{4 \pi \varepsilon_{0}}\right)^{1 / 2}\right] E^{1 / 2} .
$$

В соотношении (6) константа $K_{1}$ сильно зависит от геометрических параметров кристаллитов оксида бария, при этом первое слагаемое в правой части соотношения (6) зависит от них логарифмически, т.е. слабо. Поэтому тангенс угла наклона линейной части вольтамперной характеристики будет равен выражению в квадратных скобках в правой части соотношения (6), из которого легко может быть найден коэффициент усиления поля $K_{1}$, по которому из соотношений (4) или (5) можно определить средний размер части кристаллитов оксида бария, с которой при данной температуре имеет место максимум термоэмиссии.

Для области ограничения тока пространственным зарядом вольт-амперная характеристика зазора катод-анод описывается известным законом „трехвторых“ [15]. На рис. 2 показана схема, иллюстрирующая изменение характера вольт-амперной характеристики при изменении величины напряжения в зазоре катод-анод. На рис. 2 обозначено: 1 - катод, 2 - анод, 3 - плоскость минимума потенциала, 4 - зерна оксида бария, $x_{m}-$ расстояние от катода до плоскости минимума потенциала $U_{m}$ в зазоре катод-анод, параметры $a$ и $D$ соответствуют рис. 1 . При этом с увеличением напряжения $U$ плоскость минимума потенциала сдвигается влево в сторону катода.

Если расстояние $x_{m}$ будет больше или равно расстоянию между эмиттирующими частями кристаллитов 


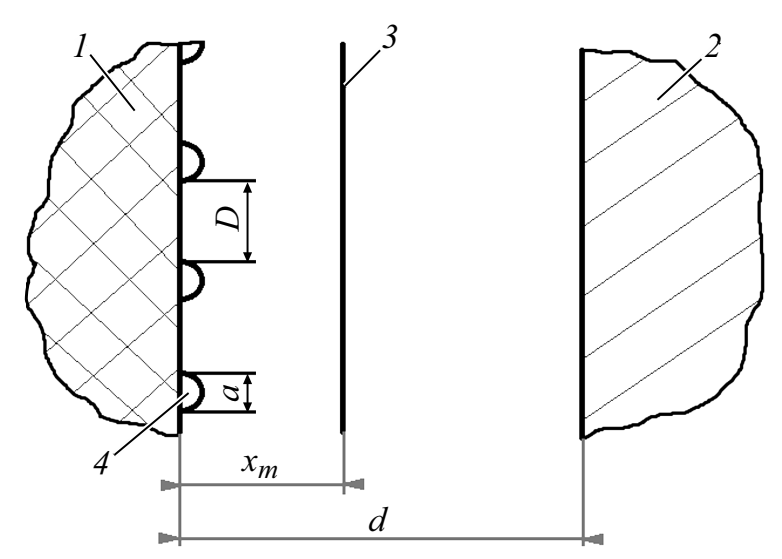

Рис. 2. Схема, иллюстрирующая изменение характера вольтамперной характеристики зазора катод-анод.

оксида бария $D$, то термоэмиссия с катода будет регистрироваться как с квазиоднородного катода в режиме „Плоского диода“. В этом случае вольт-амперная характеристика будет иметь вид [15], где $K_{2}$ - константа

$$
I=K_{2} \frac{\left(U-U_{m}\right)^{3 / 2}}{\left(d-x_{m}\right)^{2}} .
$$

Если расстояние $x_{m}$ будет меньше среднего расстояния $D$, то термоэмиссия с катода будет регистрироваться, как с набора независимых кристаллитов, каждый из которых работает в режиме сферического или цилиндрического диода. В этом случае вольт-амперная характеристика будет иметь вид [15]

$$
I=K_{3} \frac{\left(U-U_{m}\right)^{3 / 2}}{d \beta^{2}(d / a)},
$$

где $K_{3}-$ константа, $\beta-$ функция отношения $d / a$. Тогда с увеличением величины $U$ от нулевого значения на вольт-амперной характеристике в области ограничения тока пространственным зарядом появится излом, положение которого на шкале напряжений позволит определить среднее расстояние между кристаллитами оксида бария $D$. Для импрегнированного катода IC области термоэмиссии для случая ограничения тока пространственным зарядом являются квазиплоскими образованиями - шириной $a$ и длиной $L$, поэтому при дальнейшем увеличении напряжения на вольт-амперной характеристике появится второй излом.

В соответствии с [15] для плоского диода, зависимость потенциала $U$ от координаты $x$ в зазоре катод-анод может быть выражена в виде универсальной функции $\eta(\xi)$ с безразмерными переменными $\eta$ и $\xi$

$$
\begin{gathered}
\eta=\frac{e}{k T}\left(U-U_{m}\right), \\
\xi=C\left(x-x_{m}\right),
\end{gathered}
$$

где $C$ - постоянная, равная

$$
C=4\left(\frac{\pi}{2 k}\right)^{3 / 4} m^{1 / 4} e^{1 / 2} T^{-3 / 4} j^{1 / 2} .
$$

В соотношение (11) входят $e-$ заряд электрона, $m-$ масса электрона, $j$ - плотность тока насыщения термоэмиссии $j=I / S$. При этом в режиме работы „плоского диода“ площадь $S$ равна общей площади эмитирующей поверхности катода. Величина $1 / C$ имеет размерность длины. Если плотность тока выражена в $\mathrm{A} / \mathrm{cm}^{2}$, величина $C$ равна $[15]$

$$
C=9.174 \cdot 10^{5} T^{-3 / 4} j^{1 / 2}, \mathrm{~cm}^{-1} .
$$

Для нахождения среднего расстояния между кристаллитами оксида бария необходимо найти величину $x_{m}$ в точке излома вольт-амперной характеристики в области ограничения тока пространственным зарядом, т.е. для фиксированной температуры катода необходимо определить величину $I_{S}$ - ток насыщения при данной температуре катода и величину $I_{2}$ - ток катода при напряжении, при котором наблюдается излом в области ограничения тока пространственным зарядом. Далее необходимо определить величину минимума потенциала в зазоре катод-анод

$$
U_{m}=\frac{k T}{e} \ln \left(\frac{I_{S}}{I_{2}}\right)
$$

и значение параметра $\eta$

$$
\eta=\frac{e U_{m}}{k j T}=\ln \left(\frac{I_{S}}{I_{2}}\right) .
$$

По найденному значению $\eta$, используя табулированную зависимость $\eta(\xi)$, приведенную в работе [16], можно определить величину $\xi$, а по соотношениям (10) и (11) и величину $x_{m} \sim-D$.

\section{2. Методика экспериментальных исследований}

Установка для исследования параметров термоэмиссии катодных материалов собрана на базе универсального откачного поста УСУ-4. Образцы исследуемых материалов в виде таблетки диаметром $6.6 \mathrm{~mm}$ и толщиной $2 \mathrm{~mm}$ закрепляли в держателе, снабженном нагревателем и хромель-алюмелевой термопарой. На манипуляторе установки может быть одновременно размещено три держателя с образцами исследуемых материалов. Температура образца регулируется микропроцессорным терморегулятором в интервале $100-1200^{\circ} \mathrm{C}$ с точностью $0.2^{\circ} \mathrm{C}$ и шагом $1^{\circ} \mathrm{C}$. Расстояние от образца до анодного блока может устанавливаться с точностью $0.05 \mathrm{~mm}$ с помощью микрометрических головок. Анодный блок выполнен в виде металлокерамической конструкции с плоским молибденовым анодом, покрытым слоем никеля толщиной $3 \mu \mathrm{m}$. Анод имеет измерительное отверстие диаметром $1 \mathrm{~mm}$, за которым расположены антидинатронная диафрагма и коллектор в виде цилиндра Фарадея. Потенциал антидинатронной диафрагмы может 
устанавливаться в интервале $\pm 100 \mathrm{~V}$ с шагом $1 \mathrm{~V}$. Ускоряющее напряжение отрицательной полярности подается на образец и может регулироваться в диапазоне 0-600 V с шагом $0.1-5 \mathrm{~V}$. Источник ускоряющего напряжения имеет максимальный выходной ток до $30 \mathrm{~mA}$, что обеспечивает измерение параметров термоэмиссии с плотностью тока с катодного материала до $120 \mathrm{~mA} / \mathrm{cm}^{2}$. Система регистрации тока цилиндра Фарадея обеспечивает регистрацию тока в интервале $2 \cdot 10^{-3}-2 \cdot 10^{-11} \mathrm{~A}$. Это позволяет проводить измерения термоэмиссионных параметров катодных материалов вплоть до очень низких значений температуры материалов, что важно при изучении начальных этапов термоэмиссионного активирования катодов. Для повышения точности измерений система регистрации автоматически проводит от двух до десяти накоплений с усреднением результатов измерений.

Разработанная методика была апробирована на примере NOC, ANOC и IC. IC получен пропиткой вольфрамовой губки с пористостью $28 \%$ и средним размером пор $5 \mu \mathrm{m}$ алюминатом состава $2.5 \mathrm{BaO} \cdot 0.4 \mathrm{CaO} \cdot \mathrm{Al}_{2} \mathrm{O}_{3}$. Для изготовления ANOC использован порошок никеля фракции 45-71 $\mu \mathrm{m}$ и тройной карбонат состава $\mathrm{BaCO}_{3} \cdot 0.2 \mathrm{CaCO}_{3} \cdot 1.2 \mathrm{SrCO}_{3}$, при содержании в катодном материале тройного карбоната в количестве $10 \%$. Для изготовления агломератов для агломерированного ANOC использован порошок никеля фракции 10-25 $\mu \mathrm{m}$, покрытый тройным карбонатом при содержании тройного карбоната 50\%. Агломерированный катод изготовлен из смеси порошков никеля фракции 45-63 $\mu \mathrm{m}$ и агломератов фракции 45-63 $\mu \mathrm{m}$ с общим содержанием карбоната $10 \%$.

Измерения термоэмиссионных характеристик и параметров термоэмиссионной неоднородности катодных материалов были проведены после прогрева катодов в течение $1 \mathrm{~h} \mathrm{в}$ вакууме без отбора тока при температуре $950^{\circ} \mathrm{C}$ (NOC и ANOC) и при температуре $1150^{\circ} \mathrm{C}$ (IC). Данные режимы прогрева недостаточны для полного активирования катодов, однако были выбраны из тех соображений, что позволяют зарегистрировать возможную зависимость параметров $a, L$ и $D$ от температуры в процессе формирования кристаллитов оксида бария при активировании катодов, которая обусловлена неоднородностью распределения кислородных вакансий в кристаллитах оксида бария. При этом рабочая температура катодов составляет $850^{\circ} \mathrm{C}$ для $\mathrm{NOC}, 900^{\circ} \mathrm{C}$ для $\mathrm{ANOC}$ и $1050^{\circ} \mathrm{C}$ для IC.

Измерения эмиссионных свойств и параметров неоднородности эмиссионных свойств катодных материалов были проведены в интервале температур 600-680 ${ }^{\circ} \mathrm{C}$ для NOC и ANOC и в интервале температур $760-840^{\circ} \mathrm{C}$ для IC.

На рис. 3 в качестве примера приведен участок вольт-амперной характеристики импрегнированного катода для области ограничения тока пространственным зарядом при температуре $780^{\circ} \mathrm{C}$. На экспериментальной кривой рис. 3 выделяются три участка, экстраполируемые прямыми 1-3, при этом из точек пересечения этих прямых опущены перпендикуляры 4 и 5, позволяющие определить значения напряжения катод-анод, при которых наблюдаются изломы экспериментальной кривой. Перпендикуляр, обозначенный цифрой 6, отмечает значение напряжения, выше которого кривая переходит в область тока насыщения. Отметим, что для IC при всех значениях температуры наблюдаются три прямолинейных участка 1,2 и 3 и соответственно два излома экспериментальной кривой, а для NOC и ANOC наблюдаются только два прямолинейных участка 1 и 2 и соотвественно один излом экспериментальной кривой.

На рис. 4 приведен участок вольт-амперной характеристики импрегнированного катода для области тока

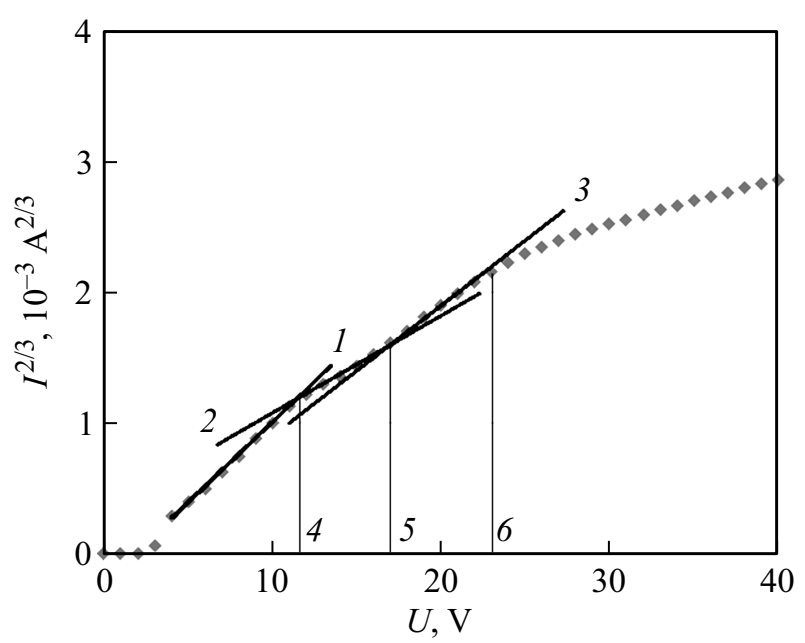

Рис. 3. Область ограничения тока пространственным зарядом термоэмиссии импрегнированного катода при температуре $780^{\circ} \mathrm{C}$.

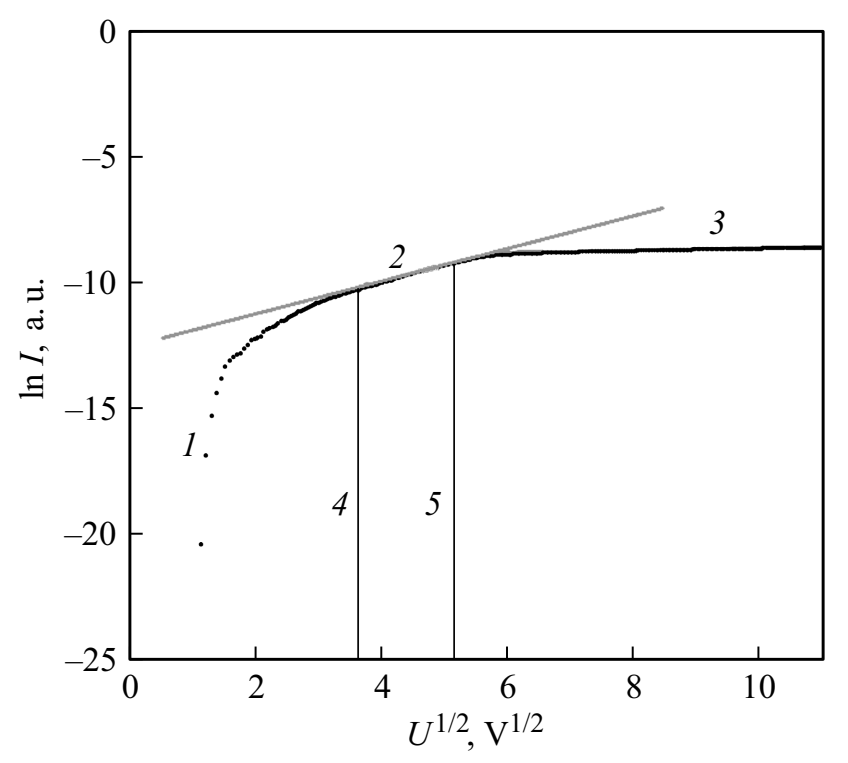

Рис. 4. Область тока насыщения термоэмиссии импрегнированного катода при температуре $780^{\circ} \mathrm{C}$. 
насыщения термоэмиссии при температуре $780^{\circ} \mathrm{C}$, где 1 - экспериментальная зависимость, 2 - экстраполирующая прямая линейного участка кривой 1 , позволяющая определить величину тока насыщения при нулевом поле в зазоре катод-анод, а также наклон линейного участка кривой 1. Перпендикуляр 4 на рис. 4 соответствует перпендикуляру 6 на рис. 3, а перпендикуляр 5 на рис. 4 - началу участка 3 , на котором наблюдаются отклонения от закона Шоттки при увеличении напряжения. Физическое обоснование отклонения от закона Шоттки, характерного для могих типов катодов и, особенно, для „скандатных“ катодов [5,6], будет рассмотрено в последующей публикации. Экспериментальные кривые рис. 3 и 4 получены при развертке напряжения катод-анод с шагом $1 \mathrm{~V}$.

\section{3. Экспериментальные результаты и их обсуждение}

При анализе экспериментальных результатов будем учитывать, что при каждой температуре максимум тока термоэмиссии катода идет с участков кристаллитов оксида бария, имеющих минимальную работу выхода, т.е. оптимальную для данной температуры концентрацию кислородных вакансий. При этом с ростом температуры значение оптимальной концентрации кислородных вакансий сдвигается в сторону более высоких их значений, что вытекает из расчетных зависимостей работы выхода оксида бария от концентрации кислородных вакансий при различных температурах, приведенных на рис. 2 в работе [9].

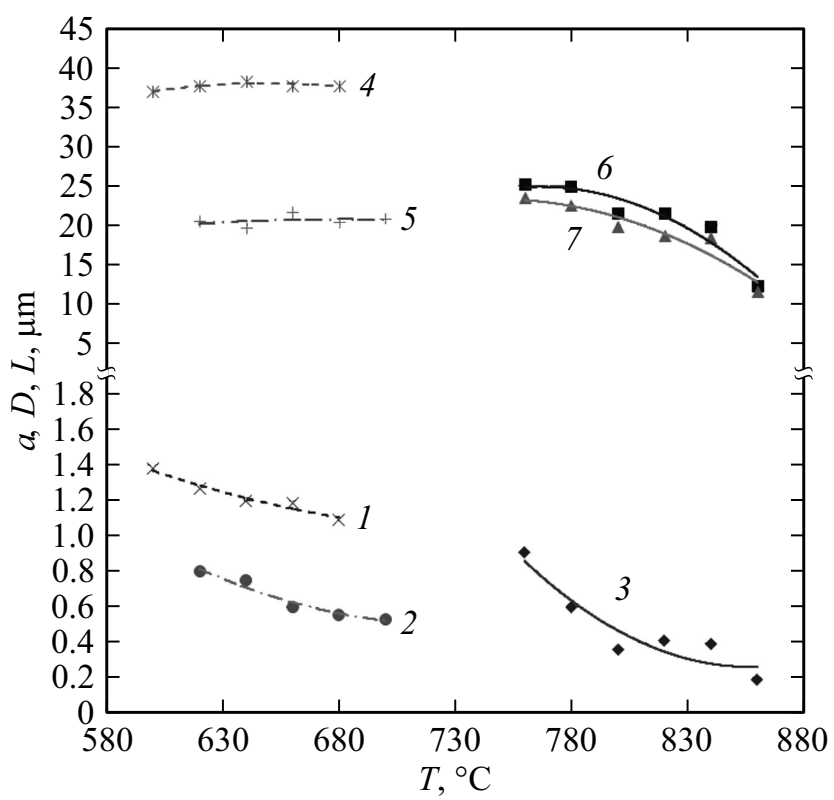

Рис. 5. Температурная зависимость среднего размера частей кристаллитов оксида бария, с которых имеет место максимум термоэмиссии при данной температуре.

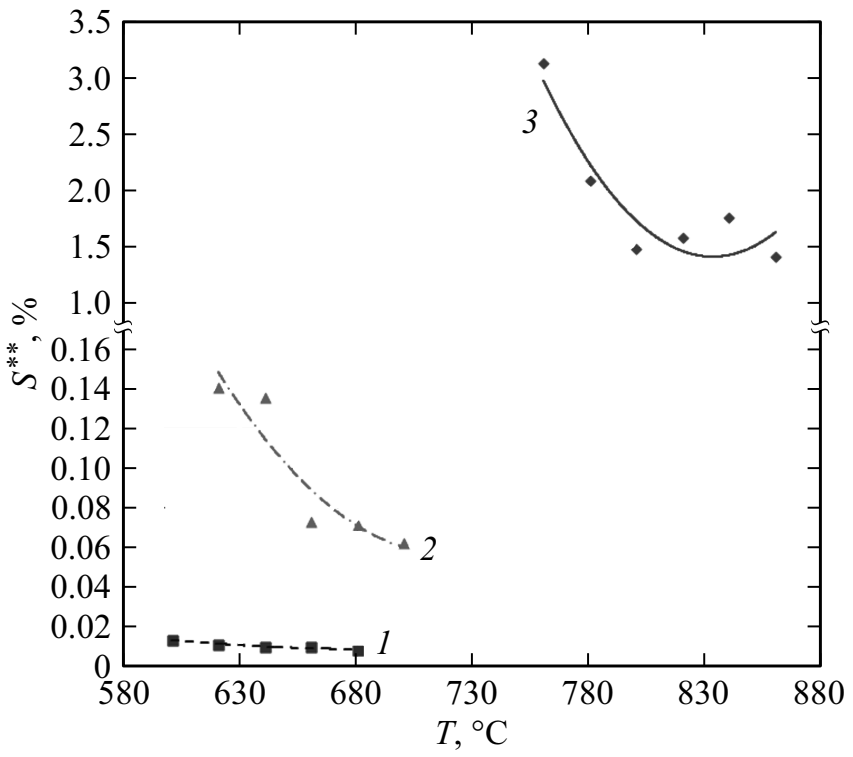

Рис. 6. Температурная зависимость площади поверхности $S^{* *}$ кристаллитов оксида бария: 1 - NOC, $2-$ ANOC, 3 - IC, с которых имеет место максимум термоэмиссии при данной температуре.

На рис. 5 приведены экспериментальные зависимости параметров $a, L$ и $D$ от температуры для исследованных типов катодов. На рисунке цифрами обозначены следующие температурные зависимости: параметр асоответственно для NOC 1, ANOC 2, IC 3, параметр $D-$ соответственно для NOC 4 , ANOC 5 , IC 6 , параметр $L$ - для IC 7.

На рис. 6 приведены экспериментальные температурные зависимости площади поверхности $S^{* *}$ кристаллитов оксида бария, сформировавшихся из карбонатной или алюминатной фаз и с поверхности которых имеет место максимум термоэмиссии. При этом величина $S^{* *}$ равна

$$
S^{* *}=S^{*} / \gamma S,
$$

выражена в процентах, а параметр $S^{*}$ берется из соотношения (2) для сферических центров эмиссии и соотношения (3) для цилиндрических. При этом параметр $n$ для простоты принят равным единице, а параметр $\gamma$ равен 0.16 для NOC и ANOC и 0.29 для IC.

Как и следовало ожидать, для NOC параметры $a, D$ и $S^{* *}$ слабо зависят от температуры. Это означает, что в таком типе катода в процессе его активирования в течение $1 \mathrm{~h}$ без отбора тока формируются сравнительно небольшие и однородные по концентрации кислородных вакансий кристаллиты оксида бария, при этом эффективная площадь поверхности таких кристаллитов очень мала. Эти особенности оксидно-никелевого катода обусловлены сравнительно низкой активирующей и катализирующей способностью никеля [8], к тому же взаимодействующего с карбонатной фазой в местах их точечных контактов. 


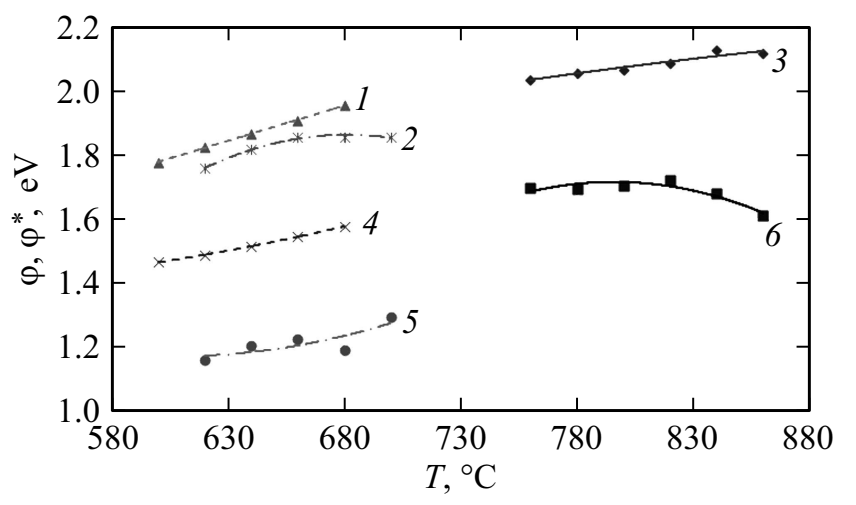

Рис. 7. Температурная зависимость работы выхода катода „по полному току“.

Для ANOC средний размер центров эмиссии ниже, чем для оксидно-никелевого катода, однако растет с ростом температуры, при этом среднее расстояние между кристаллитами ниже, чем для NOC. Это означает, что в кристаллитах оксида бария в таком катоде имеет место заметная неоднородность распределения кислородных вакансий. Это связано с тем, что в качестве катализатора при формировании кристаллитов оксида бария из тройного карбоната в ANOC принимают участие не только основные зерна никеля из состава катода, но и зерна никеля из состава агломератов, при этом и активация кристаллитов оксида бария (накопление в них кислородных вакансий) идет с двух сторон кристаллитов. В соответствии с этим и эффективная площадь эмиттирующей поверхности в таком катоде существенно выше, чем для катода типа NOC.

Для IC параметры $L$ и $D$ слабо зависят от температуры, в то время как параметр $a$ с ростом температуры уменьшается примерно в 7 раз. Это связано с тем, что вольфрам в IC является более эффективным активатором кристаллитов оксида бария в смысле генерации в них кислородных вакансий по сравнению с никелем в NOC и ANOC. B связи с этим концентрация кислородных вакансий в кристаллитах оксида бария в IC существенно растет в направлении от алюмината к вольфраму на их границе в соответствии с рис. 1.

Величина работы выхода „по полному току“ может быть определена с использованием известного выражения [15]

$$
\varphi^{*}=k T \ln \left[\frac{S^{*} A_{0} T^{2}}{I_{\mathrm{sat}}}\right],
$$

где $I_{\text {sat }}-$ величина тока насыщения, определяемого экстраполяцией прямой 2 на рис. 4 к значению $U=0$.

На рис. 7 приведены экспериментальные температурные зависимости эффективных значений работы выхода катодных материалов $\varphi$ без учета неоднородности катодов для NOC 1, ANOC 2, IC 3, т. е. при условии $S^{*}=S$ в соотношении (16). На этом же рисунке приведены истинные значения работы выхода $\varphi^{*}$ катодных материалов, рассчитанные с использованием соотношения (16) и результатов, приведенных на рис. 6, для NOC 4, ANOC 5, IC 6. При определении эффективной эмиттирующей поверхности нами было принято $n=1$. Если же $n>1$, то систематическая погрешность определения параметра $\varphi^{*}$ для $n=2-4$ составит

$$
\Delta \varphi^{*}=k T \ln (n) \approx 0.05-0.10 \mathrm{eV} .
$$

Анализ результатов рис. 7 показывает, что дополнительное введение никеля в составе агломератов в ANOC по сравнению с NOC обеспечивает более эффективное активирование катодов, т. е. снижение и эффективной, и истинной работы выхода катодного материала.

На рис. 8 приведены расчетные температурные зависимости работы выхода оксида бария при концентрации кислородных вакансий $N_{V}$, равной: $1-1 \cdot 10^{23}, 2-$ $1 \cdot 10^{24}, 3-1 \cdot 10^{25}, 4-1 \cdot 10^{26}, 5-1 \cdot 10^{27}, 6-$ $5 \cdot 10^{27}, 7-1 \cdot 10^{28} \mathrm{~m}^{-3}$. При расчетах были использованы физическая модель и уравнения работы [10]. В соответствии с результатами работы [10] для интервала температур 900-1200 К оптимальными значениями концентрации кислородных вакансий в оксиде бария являются концентрации в интервале $1 \cdot 10^{26}-1 \cdot 10^{27} \mathrm{~m}^{-3}$. Для указанного интервала концентрации кислородных вакансий, как следует из рис. 8, не только работа выхода, но и температурный коэффициент работы выхода имеют минимальные значения, при этом работа выхода монотонно растет с ростом температуры. Поэтому прямолинейный вид и практически одинаковый наклон кривых 4 и 5 на рис. 7 подтверждает, что предварительный прогрев катодов такого типа в течение $1 \mathrm{~h}$ достаточен для полной и однородной активации кристаллитов оксида бария, сформировавшихся в результате прогрева катодов. В то же время уменьшение истинной работы выхода с ростом температуры для IC (кривая 6 на рис. 7) с учетом характера кривой 3 на рис. 5 свидетельствует о том, что для данного типа катода прогрев его в течение $1 \mathrm{~h}$ недостаточен для полной и однородной активации

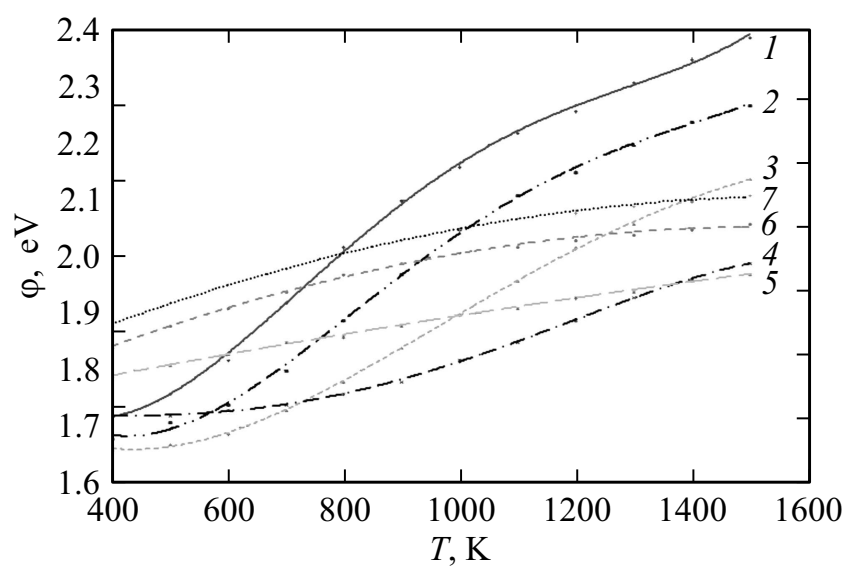

Рис. 8. Расчетные зависимости работы выхода оксида бария от температуры при различных значениях концентрации кислородных вакансий. 
кристаллитов оксида бария из-за высокой эффективности вольфрама при генерации кислородных вакансий в кристаллитах оксида бария.

\section{Заключение}

1. Прецизионные измерения вольт-амперных характеристик катодных материалов, т.е. регистрация их с шагом $0.1-0.2 \mathrm{~V}$ с последующим анализом их характера, позволяет определить параметры неоднородности катодного материала - температурные зависимости среднего размера центров термоэмиссии на поверхности катодов, среднего расстояния между центрами термоэмиссии, относительной площади эмиссионно-активной поверхности катодов.

2. Учет параметров неоднородности катодных материалов позволяет определить эффективные и истинные значения работы выхода эмиссионно-активных центров на поверхности катодов, а также их температурные зависимости, что дает информацию о степени и характере однородности активирования кристаллитов оксида бария, являющихся эмиссионно-активными центрами на поверхности катодов.

3. Для получения достоверных результатов анализ вольт-амперных характеристик следует проводить от нулевых значений напряжения катод-анод в сторону его увеличения для корректного выделения прямолинейных участков вольт-амперных характеристик в области ограничения тока пространственным зарядом и в области эффекта Шоттки.

\section{Список литературы}

[1] Дюбуа Б.Ч., Култашев О.К., Поливникова О.В. // Электронная техника. Сер. 1. СВЧ-техника. 2008. Вып. 4 (497). C. 3-22.

[2] Дюбуа Б.Ч., Королев А.Н. // Электронная техника. Сер. 1. СВЧ-техника. 2011. Вып. 1 (509). С. 5-25.

[3] Леденщова Н.Е., Ли И.П., Петров В.С., Капустин В.И. // Тонкие химические технологии. 2016. Т. 11. № 3. С. 74-81.

[4] Schoenbeck L. // Partial Fulfillment of the Requirements for the Degree Master of Science in Materials Science and Engineering. Georgia Institute of Technology, 2005. $118 \mathrm{p}$

[5] Gartner G., Geintter P., Ritz A. // Appl. Surf. Sci. 1997. N 111. P. 11-17.

[6] Shih A., Yater J., Hor C., Abrams R. // Appl. Surf. Sci. 1997. Vol. 111. P. 251-258.

[7] Yang F., Wang J., Liu W., Liu X., Zhou M. // Appl. Surf. Sci. 2013. Vol. 270. P. 746-750.

[8] Капустин В.И., Ли И.П., Петров В.С., Леденцова Н.Е., Турбина А.В. // Электронная техника. Сер. 1. СВЧтехника. 2016. Вып. 1 (528). С. 8-18.

[9] Капустин В.И., Ли И.П., Шуманов А.В., Лебединский Ю.Ю., Заблочкий А.В. // ЖТФ. 2017. Т. 62. Вып. 1. C. 106-116. (Kapustin V.I., Li I.P., Shumanov A.V., Lebedinskii Yu.Yu., Zablotskii A.V. // Tech. Phys. 2017. Vol. 62. N 1. P. 116-126.)
[10] Капустин В.И. // Перспективные материалы. 2000. № 2. C. 5-17.

[11] Brodie I., Vancil B. // IEEE IVEC. 2014. Book Abstracts. P. 53-54.

[12] Vaughn J.M. // Partial fulfillment of the requirements for the degree Doctor of Philosophy. The faculty of the College of Arts and Sciences of Ohio University, USA. 2010. 193 p.

[13] Wang Y., Wang J., Liu W., Liang W., Yang F. // IEEE IVEC. 2014. Book Abstracts. P. 51-52.

[14] Марин В.В., Капустин В.И., Никитин О.В. // Наукоемкие технологии. 2003. № 2. С. 50-57.

[15] Добрецов Л.Н., Гомоюнова М.В. Эмиссионная электроника. М.: Наука, 1966. 564 с.

[16] Царев Б.М. Расчет и конструирование электронных ламп. М.: Энергоиздат, 1916. 235 с. 